\title{
Genetic analysis of body weight in South African Angora kids and young goats
}

\author{
M.A. Snyman
}

Grootfontein Agricultural Development Institute, Private Bag X529, Middelburg (EC), South Africa, 5900

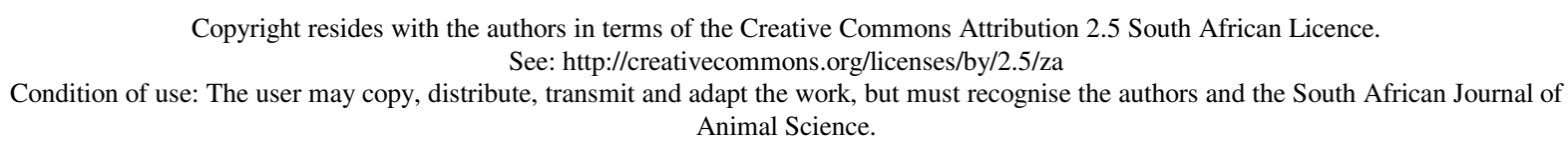

\begin{abstract}
The data used for this study consisted of 27485 kid records, the progeny of 599 sires and 10077 dams, and were collected on the 2000- to 2009-born kids of 11 Angora goat studs. Variance and covariance components and ratios pertaining to direct additive genetic variation, maternal additive genetic variation, maternal permanent environmental variation, and the relationship between direct and maternal effects for birth weight (BW; $\mathrm{kg}$ ), weaning weight (WW; kg) and body weight at 8, 12 and 16 months (W8, W12 and W16; kg) were estimated with the ASReml program. Direct additive heritability estimates of $0.22,0.20,0.12,0.34$ and 0.58 were obtained for BW, WW, W8, W12 and W16, respectively. Maternal heritabilities were 0.10, 0.09, 0.03 and 0.06 for BW, WW, W8 and W12, respectively, while maternal environmental effects of $0.13,0.11,0.06$ and 0.04 were estimated for the latter traits, respectively. An unfavourable correlation of -0.38 was obtained between direct and maternal genetic effects for BW. Low to medium positive direct genetic correlations were estimated between birth weight and body weights recorded at a later stage in life. High positive direct genetic correlations were estimated among WW, W8, W12 and W16. The maternal genetic correlations obtained between birth weight and the other body weights were medium to high. Phenotypic correlations among the traits ranged from low to high. Genetic trends of body weight at different ages indicate that although not many breeders use objective measurement as a selection tool, body weight increased slightly in the 11 studs over the 10-year study period. Since reproduction and body weight should be included in a selection programme for Angora goats, the relationship between the direct and maternal additive effects should be clarified. The importance of a sufficiently structured and related pedigree, especially on the part of the dams and maternal grand dams, has been highlighted in this study. As this is one of the constraints of this data set, data collection in the Angora goat industry should continue until a suitably structured data set has been built up that could be used to estimate multi-trait breeding values for the industry.
\end{abstract}

Keywords: Birth weight, genetic parameters, maternal effects, weaning weight

Corresponding author: grethasn@daff.gov.za

\section{Introduction}

Body weight is one of the most important selection criteria in almost any sheep- and goat-breeding enterprise. In many sheep breeds, continuous selection for increased body weight has led to a situation where a further increase in body weight is contra-indicated. This is not the case in Angora goats, however, where there is still a positive relationship between ewe body weight and reproductive performance (Snyman, 2010a). Many of the problems encountered in Angora goats - such as high kid mortality rates (Snyman, 2010b), poor post weaning growth rates (Snyman, 2007) and low reproductive rate of young ewes (Snyman, 2010a) - could be linked to body weight. Body weight should therefore be one of the most important criteria in the selection programme of Angora goats. Angora goat stud breeders use a selection index that emphasizes increasing body weight (Snyman et al., 1996). However, not many use performance testing and objective measurement of body weight. Much of the selection for body weight that is done in breeding sires is subjective.

The most appropriate genetic model should be applied when breeding values for any trait are estimated in practice. Numerous studies have investigated the importance of applying the most appropriate model to estimate (co)variance components and genetic parameters for traits that are influenced by maternal effects in various 
species and breeds (Gerstmayr, 1991; Hagger \& Schneeberger, 1995; Robinson, 1996; Vaez Torshizi et al., 1996; Yazdi et al., 1997; Larsgard \& Olesen, 1998; Analla et al., 1999; Lewis \& Beatson, 1999; Ligda et al., 2000; Maniatis \& Pollott, 2003; Norris et al., 2004; Iwaisaki et al., 2005; Mandal et al., 2006; Miraei-Ashtiani et al., 2007; Boujenane \& Hazzab, 2008; Mandal et al., 2008; Van Wyk et al., 2008). There is a dearth of information on the heritability of body weight and growth traits in goats in general (Bosso et al., 2007; Boujenane \& Hazzab, 2008; Zhang et al., 2008; Gowane et al., 2011; Rashidi et al., 2011) and in Angora goats specifically, particularly the influence of maternal effects on these traits (Snyman \& Olivier, 1996).

The objectives of this study were, first, to determine the most appropriate models of analysis for body weight of Angora goat kids at different ages; second, to estimate (co)variance components and genetic parameters for these traits; and, third, to evaluate the genetic trends in body weight in the 11 studs over the ten-year study period. Information generated by this study will be applied to estimate breeding values for growth performance of animals in the South African Angora goat industry.

\section{Materials and Methods}

The data were collected on the 2000- to 2009-born kids of 11 Angora goat studs. The data file comprised 27485 records after editing. Traits analysed were birth weight (BW; kg), weaning weight (WW; kg) and body weight at 8,12 and 16 months (W8, W12 and W16; kg). Birth weight, weaning weight and 8-month body weights were recorded on both male and female kids, while 12- and 16-month body weights were recorded only for the female kids, with the exception of two studs where male kids were recorded.

Basic editing was performed on the original data set. Animals that had been reared artificially or had missing information on birth date, sex, age of the dam, and dam identification were omitted. All the available pedigree information was included in all the analyses to increase the accuracy of parameter estimation through the use of all the obtainable relationships among animals in the data set. The number of animals in the pedigree file was 35 924, while the numbers of sires and dams with progeny in the data set for birth weight were 599 and 10077 , respectively. The number of animals in the pedigree file with unknown sires was 7264.

The data were initially analysed by least-squares methods to identify the non-genetic effects that contributed significantly to variation, using the general linear model (GLM) procedure of the SAS computer package (SAS, 2009). The fixed effects included in the final model for BW were herd-year of birth (HY), sex (male and female), birth status of the kid (1, 2 or 3) and age of dam (1 to 10 years). For WW, W8, W12 and W16, fixed effects for herd-year-rearing group (HYGR), sex, rearing status of the kid (11, 21, 22, 31, 32, 33), age of dam, and a linear covariate for age of the kid at weighing (age in days) were included. The reason for including the combined HYGR effect is that different rearing strategies were followed in the various studs from birth till weaning and after weaning, and the rearing groups in the studs were not the same (Gerstmayr \& Horst, 1995).

(Co)variance components were estimated with Gilmour et al.'s (2009) ASReml programme. Single-trait animal models were fitted for all traits. Direct additive and maternal additive genetic effects, with or without a covariance between them, and maternal permanent environmental effects were tested for all traits in different combinations to yield six models.

The six models were:

$$
\begin{aligned}
& \mathbf{y}=X \mathbf{b}+Z_{1} \mathbf{a}+\mathbf{e} \\
& \mathbf{y}=X \mathbf{b}+Z_{1} \mathbf{a}+Z_{2} \mathbf{c}+\mathbf{e} \\
& \mathbf{y}=X \mathbf{b}+Z_{1} \mathbf{a}+Z_{2} \mathbf{m}+\mathbf{e} ; \text { with } \operatorname{cov}(\mathrm{a}, \mathrm{m})=0 \\
& \mathbf{y}=X \mathbf{b}+Z_{1} \mathbf{a}+Z_{2} \mathbf{m}+\mathbf{e} ; \text { with } \operatorname{cov}(\mathrm{a}, \mathrm{m})=A \sigma_{\mathrm{am}} \\
& \mathbf{y}=X \mathbf{b}+Z_{1} \mathbf{a}+Z_{2} \mathbf{m}+Z_{3} \mathbf{c}+\mathbf{e} ; \text { with } \operatorname{cov}(\mathrm{a}, \mathrm{m})=0 \\
& \mathbf{y}=X \mathbf{b}+Z_{1} \mathbf{a}+Z_{2} \mathbf{m}+Z_{3} \mathbf{c}+\mathbf{e} ; \text { with } \operatorname{cov}(\mathrm{a}, \mathrm{m})=A \sigma_{\mathrm{am}}
\end{aligned}
$$

where $\mathbf{y}$ is a vector of observed traits of animals; $\mathbf{b}, \mathbf{a}, \mathbf{m}$ and $\mathbf{c}$ are vectors of fixed effects, direct additive genetic effects, maternal additive genetic effects and maternal permanent environmental effects, respectively; $X, Z_{1}, Z_{2}$ and $Z_{3}$ are incidence matrices, respectively relating fixed effects, direct additive genetic effects, maternal additive genetic effects and maternal permanent environmental effects to $\mathbf{y} ; \mathbf{e}$ is the vector of residuals; $\mathrm{A}$ is a numerator relationship matrix, and $\sigma_{\mathrm{am}}$ is the covariance between direct additive genetic and maternal additive genetic effects. It was assumed that $\mathrm{V}(\mathrm{a})=\mathrm{A} \sigma_{\mathrm{a}}^{2} ; \mathrm{V}(\mathrm{m})=\mathrm{A} \sigma_{\mathrm{m}}^{2} ; \mathrm{V}(\mathrm{c})=\mathrm{I} \sigma_{\mathrm{c}}^{2} ; \mathrm{V}(\mathrm{e})=\mathrm{I} \sigma_{\mathrm{e}}^{2}$, where $\mathrm{I}$ is an identity matrix, and $\sigma_{\mathrm{a}}^{2}, \sigma_{\mathrm{m}}^{2}, \sigma_{\mathrm{c}}^{2}$ and $\sigma_{\mathrm{e}}^{2}$ are the direct additive genetic variance, maternal additive genetic variance, maternal 
permanent environmental variance and environmental variance, respectively. All components, with the phenotypic variance $\left(\sigma_{\mathrm{p}}^{2}\right)$ being the sum of ${\sigma_{\mathrm{a}}^{2}}_{\mathrm{a}}, \sigma_{\mathrm{m}}^{2}, \sigma_{\mathrm{am}}, \sigma_{\mathrm{c}}^{2}$, and $\sigma_{\mathrm{e}}^{2}$, were derived at convergence.

Log likelihood ratio tests were carried out among all six models to determine the most appropriate model for each trait (Morrell, 1998). The likelihood ratio statistic is $\log \left(\sigma \square=L\left(\mathrm{~b}_{2}\right)-L\left(\mathrm{~b}_{1}\right)\right.$, where $L(\mathrm{~b})$ is the $\log$ likelihood function evaluated at the maximum likelihood estimator (b). The statistic $-2\left(\log L_{2}-\log L_{1}\right)$ has a $\chi^{2}$ distribution with degrees of freedom equal to the difference between the number of parameters for the two models being compared. An effect was considered to have a significant influence when its inclusion caused a significant increase in log likelihood, compared with the model in which it was ignored. For the purpose of this study a significance level of $P<0.05$ was applied throughout.

Depending on the model, variance ratios were computed as direct heritability $\left(\mathrm{h}^{2}=\sigma_{\mathrm{a}}{ }^{2} / \sigma_{\mathrm{p}}{ }^{2}\right)$, maternal heritability $\left(\mathrm{m}^{2}=\sigma_{\mathrm{m}}{ }^{2} / \sigma_{\mathrm{p}}{ }^{2}\right)$ and the direct-maternal covariance as proportion of phenotypic variance $\left(\mathrm{c}_{\mathrm{AM}}=\sigma_{\mathrm{am}} / \sigma_{\mathrm{p}}{ }^{2}\right)$, with a corresponding estimate of the direct-maternal correlation $\left[\mathrm{r}_{\mathrm{am}}=\mathrm{c}_{\mathrm{am}} / \sqrt{ }\left(\sigma_{\mathrm{a}}{ }^{2} \times \sigma_{\mathrm{m}}{ }^{2}\right)\right]$. Similarly, the maternal environmental variance ratio was estimated by the permanent maternal environmental variance as a proportion of $\sigma_{\mathrm{p}}^{2}\left(\mathrm{p}^{2}=\sigma_{\mathrm{c}}^{2} / \sigma_{\mathrm{p}}^{2}\right)$.

Subsequently, multi-trait analyses were done to estimate covariance components and correlations among BW, WW, W8, W12 and W16, using the most suitable model for each trait, as determined under single-trait analyses.

Estimated breeding values of individual animals were also obtained with ASReml. In order to estimate the genetic trends, means of estimated breeding values for kids within year of birth were calculated. Genetic trends were obtained by regression means of estimated breeding values on year of birth for each trait. These procedures were carried out with the SAS computer package (SAS, 2009).

\section{Results and Discussion}

The number of records analysed for each trait, as well as the average and coefficient of variation for each trait, are summarised in Table 1. Various rearing strategies had been followed in the studs, as was discussed by Snyman (2007). In most of them, the ram kids received supplementary feeding from weaning until 8 months. For most of those studs where the ram kids were run under veld conditions after weaning without supplementation, 12- and 16-month body weights were available, while these weights were not available for those studs in which the ram kids were fed after weaning. That explains why it seems that the ram kids lost body weight from 8 to 12 months.

The different feeding strategies caused a large variation in average body weight between the studs at the various ages, which increased the total variation in body weight in the animal population used for this study, hence the relatively high coefficients of variation obtained.

Table 1 Number of records in the final data set, as well as average and coefficient of variation for body weight at different ages for ram and ewe Angora goat kids

\begin{tabular}{lccccc}
\hline Body weight & Rams & Ewes & CV (\%) & Rams (n) & Ewes (n) \\
\hline Birth weight $(\mathrm{kg})$ & $3.06 \pm 0.02$ & $2.84 \pm 0.02$ & 18.61 & 11015 & 10627 \\
Weaning weight $(\mathrm{kg})$ & $16.41 \pm 0.24$ & $15.11 \pm 0.18$ & 25.41 & 11903 & 11718 \\
8-month body weight $(\mathrm{kg})$ & $25.39 \pm 0.55$ & $17.34 \pm 0.30$ & 30.34 & 5787 & 6517 \\
12-month body weight $(\mathrm{kg})$ & $24.02 \pm 0.30$ & $19.64 \pm 0.29$ & 25.50 & 1890 & 4786 \\
16-month body weight $(\mathrm{kg})$ & $29.15 \pm 0.46$ & $22.79 \pm 0.45$ & 26.31 & 1440 & 4787 \\
\hline
\end{tabular}

In Table 2 the number of records in the final data set for estimation of correlations between the various body weights is presented. The estimated variance and covariance components obtained under the most suitable model for each trait analysed, as well as the genetic parameters calculated for the traits, are summarised in Table 3. 
Table 2 Number of records in the final data set for estimation of correlations between body weights

\begin{tabular}{lc}
\hline Trait $(\mathrm{kg})$ & Number of records \\
\hline Birth weight \& weaning weight & 19064 \\
Birth weight \& 8-month body weight & 10966 \\
Birth weight \& 12-month body weight & 6005 \\
Birth weight \& 16-month body weight & 5161 \\
Weaning weight \& 8-month body weight & 12180 \\
Weaning weight \& 12-month body weight & 6604 \\
Weaning weight \& 16-month body weight & 6167 \\
8-month body weight \& 12-month body weight & 5888 \\
8-month body weight \& 16-month body weight & 5348 \\
12-month body weight \& 16-month body weight & 4640 \\
\hline
\end{tabular}

Table 3 Variance and covariance components and genetic parameter estimates $( \pm$ SE) for body weight from birth to 16 months

\begin{tabular}{lccccc}
\hline Parameter & Birth weight & $\begin{array}{c}\text { Weaning } \\
\text { weight }\end{array}$ & $\begin{array}{c}\text { 8-month } \\
\text { body weight }\end{array}$ & $\begin{array}{c}\text { 12-month } \\
\text { body weight }\end{array}$ & $\begin{array}{c}\text { 16-month } \\
\text { body weight }\end{array}$ \\
\hline $\begin{array}{l}\text { Best model } \\
\text { Variance components: }\end{array}$ & Model 6 & Model 5 & Model 5 & Model 5 & Model 1 \\
$\quad$ Total phenotypic & 0.236 & 10.230 & 17.260 & 11.120 & 19.910 \\
$\quad$ Direct additive & 0.053 & 2.054 & 1.992 & 3.808 & 11.521 \\
$\quad$ Maternal additive & 0.024 & 0.870 & 0.455 & 0.621 & \\
$\quad$ Covariance between & -0.013 & & & & \\
$\quad$ animal effects & 0.030 & 1.097 & 0.971 & 0.440 & \\
$\quad \begin{array}{l}\text { Permanent environment } \\
\text { Residual }\end{array}$ & 0.143 & 6.212 & 13.844 & 6.255 & 8.388 \\
$\quad$ Variance ratios: & & & & & \\
$\quad \begin{array}{l}\text { Direct heritability } \\
\text { Maternal heritability }\end{array}$ & $0.22 \pm 0.02$ & $0.20 \pm 0.02$ & $0.12 \pm 0.02$ & $0.34 \pm 0.04$ & $0.58 \pm 0.03$ \\
$\quad \begin{array}{l}\text { Dam permanent } \\
\text { environment }\end{array}$ & $0.13 \pm 0.03$ & $0.09 \pm 0.02$ & $0.03 \pm 0.02$ & $0.06 \pm 0.03$ & \\
$\quad \begin{array}{l}\text { Genetic correlation } \\
\text { between animal effects }\end{array}$ & $-0.38 \pm 0.10$ & $0.11 \pm 0.02$ & $0.06 \pm 0.02$ & $0.04 \pm 0.03$ & \\
\hline
\end{tabular}

For birth weight, Model 6 had the highest log likelihood (Table 3) and provided the most significant fit of all six models tested. Model 5 proved to be the most appropriate model for weaning weight, W8 and W12, while Model 1 provided the best fit for W16.

Limited information is available for heritability of early growth traits in Angora goats. All the available estimates are for body weight at 8 months and older, and most of these are based on sire model analyses (Yalcin, 1982; Nicoll, 1985; Nicoll et al., 1989; Gifford et al., 1991; Snyman \& Olivier, 1996; 1999). The heritabilities estimated in this study with animal models fall within the range (0.10 to 0.47$)$ reported in the literature (above) for body weight in Angora goats.

Similar genetic parameters were estimated for WW and for BW. Estimates of direct heritability increased from 0.12 for W8, to 0.34 for W12 and 0.58 for W16. This is in accordance with estimates obtained for sheep (Snyman et al., 1995; Safari \& Fogarty, 2003; Safari et al., 2005; 2007). 
Direct additive effects and maternal effects in birth weight and weaning weight were equally important, as is evident from the estimates of 0.22 and 0.20 for direct heritability, and of 0.23 and 0.20 for the total maternal component for birth weight and weaning weight, respectively. The total maternal component remained constant at approximately 0.10 for W8 and W12. Maternal heritability decreased only slightly from 0.10 for W8 to 0.06 for W12. It has been demonstrated that the additive maternal effect is still present for body weight at 12 months (Safari \& Fogarty, 2003; Van Wyk et al., 2008), although in most instances $\mathrm{m}^{2}$ estimates were lower than the 0.06 obtained for Angora goats in the present study.

An unfavourable correlation of -0.38 was estimated between direct and maternal genetic effects. Birth weight was the only trait in the study where $r_{a m}$ was significant. No other $r_{a m}$ estimates are available in the literature for any traits in Angora goats. Negative correlations were also reported for early body weight in Boer goats (Zhang et al., 2008), Draa goats (Boujenane \& Hazzab, 2008), Sirohi goats (Gowane et al., 2011) and Markhoz goats (Rashidi et al., 2011). However, conflicting estimates, pertaining to sign and magnitude, were reported for a wide range of sheep breeds, as summarised by Safari \& Fogarty (2003). Apart from discrepancies caused by various models and real differences between populations that were analysed, differences in data structure and size could play an important role (Gerstmayer, 1991; Meyer, 1992; Robinson, 1996). According to Maniatis \& Pollott (2003), estimation of the correlation between direct and maternal genetic effects is dependent on key pedigree relationships. It is essential to have a high proportion of dams and maternal grand dams with their own records. Because the data set used for the present study was collected over only 10 years, it could lack the optimum pedigree structure for accurate and reliable estimates of direct-maternal covariance components.

Direct genetic and phenotypic correlations among body weights at the different ages are presented in Table 4, while maternal genetic correlations between birth weight and the other recorded body weights are given in Table 5 .

Low to medium positive direct genetic correlations were estimated between birth weight and body weights recorded at a later stage in life. High positive direct genetic correlations were estimated among WW, W8, W12 and W16. Similar correlations were obtained among early body weights for other goat breeds (Bosso et al., 2007; Boujenane \& Hazzab, 2008; Zhang et al., 2008; Gowane et al., 2011; Rashidi et al., 2011). The maternal genetic correlations obtained between birth weight and the other body weights were medium to high. Similar maternal correlations were obtained between birth weight and other body weights for various sheep breeds (Safari \& Fogarty, 2003). Phenotypic correlations among the traits ranged from low to high.

Table 4 Direct genetic (above diagonal) and phenotypic (below diagonal) correlations among body weights at different ages

\begin{tabular}{lccccc}
\hline Trait & Birth weight & $\begin{array}{c}\text { Weaning } \\
\text { weight }\end{array}$ & $\begin{array}{c}\text { 8-month body } \\
\text { weight }\end{array}$ & $\begin{array}{c}\text { 12-month body } \\
\text { weight }\end{array}$ & $\begin{array}{c}\text { 16-month } \\
\text { body weight }\end{array}$ \\
\hline Birth weight & - & $0.36 \pm 0.07$ & $0.29 \pm 0.10$ & $0.35 \pm 0.11$ & $0.57 \pm 0.09$ \\
Weaning weight & $0.29 \pm 0.01$ & - & $0.93 \pm 0.02$ & $0.82 \pm 0.02$ & $0.73 \pm 0.03$ \\
8-month body weight & $0.25 \pm 0.01$ & $0.60 \pm 0.01$ & - & $0.97 \pm 0.01$ & $0.94 \pm 0.01$ \\
12-month body weight & $0.24 \pm 0.01$ & $0.65 \pm 0.01$ & $0.83 \pm 0.01$ & - & $0.98 \pm 0.01$ \\
16-month body weight & $0.24 \pm 0.01$ & $0.54 \pm 0.01$ & $0.76 \pm 0.01$ & $0.80 \pm 0.01$ & - \\
\hline
\end{tabular}

Table 5 Maternal genetic correlations between birth weight and body weight at different ages

\begin{tabular}{lcccc}
\hline Trait & $\begin{array}{c}\text { Weaning } \\
\text { weight }\end{array}$ & $\begin{array}{c}\text { 8-month body } \\
\text { weight }\end{array}$ & $\begin{array}{c}\text { 12-month body } \\
\text { weight }\end{array}$ & $\begin{array}{c}\text { 16-month } \\
\text { body weight }\end{array}$ \\
\hline Birth weight & $0.44 \pm 0.04$ & $0.61 \pm 0.08$ & $0.64 \pm 0.11$ & $0.55 \pm 0.19$ \\
\hline
\end{tabular}


Genetic trends in body weight at various ages are illustrated in Figures 1 to 4 . Figure 1 shows that there was virtually no increase in birth weight over the 10 -year period $(+0.04 \mathrm{~kg})$ as far as the direct trend is concerned. Despite the negative correlation of -0.38 estimated between direct and maternal effects for birth weight, there was no discernible maternal genetic trend over this period in birth weight.

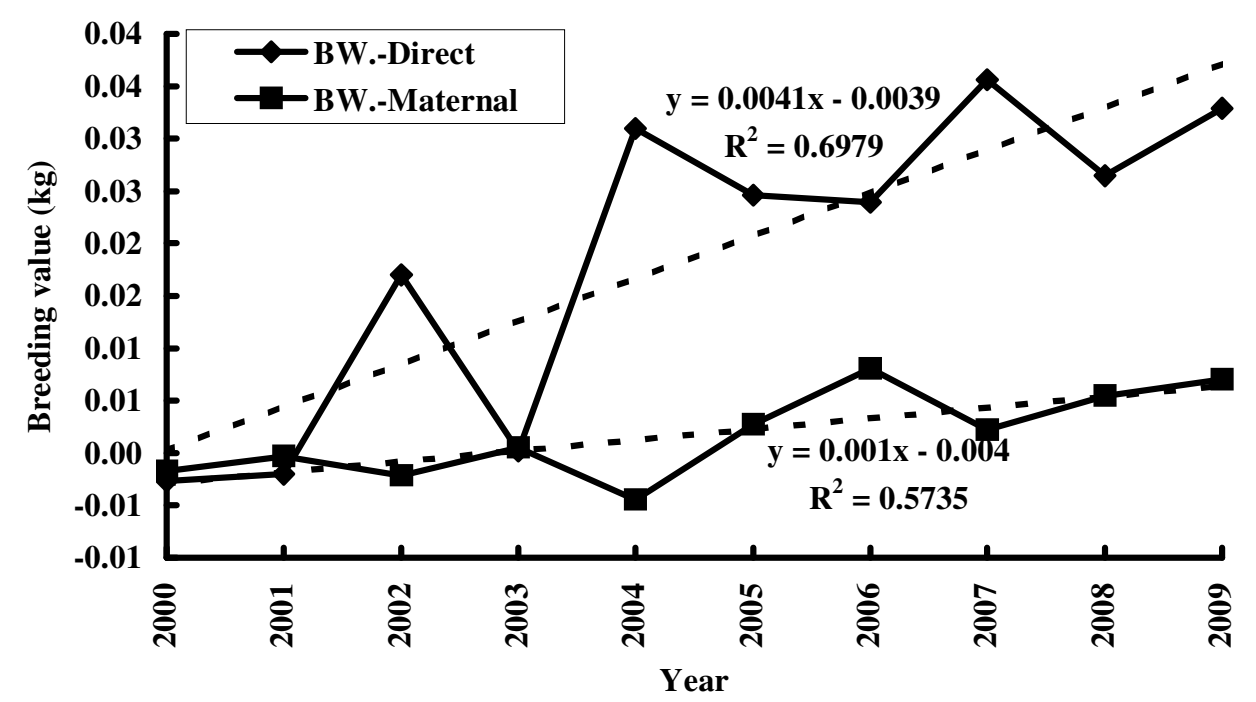

Figure 1 Direct and maternal genetic trends in birth weight (BW) in various Angora goat studs over a 10-year period.

Weaning weight increased genetically by $0.57 \mathrm{~kg}$ over the 10 -year period $(0.0567 \mathrm{~kg}$ per year; Figure 2$)$, while 8 -month body weight increased by $0.35 \mathrm{~kg}$ over the same period $(0.035 \mathrm{~kg}$ per year; Figure 3$)$. There was no obvious maternal genetic trend for either of these traits. There was a direct genetic trend in 16-month body weight of $0.11 \mathrm{~kg}$ per year, amounting to a $1.1 \mathrm{~kg}$ improvement over the 10 -year period (Figure 4 ).

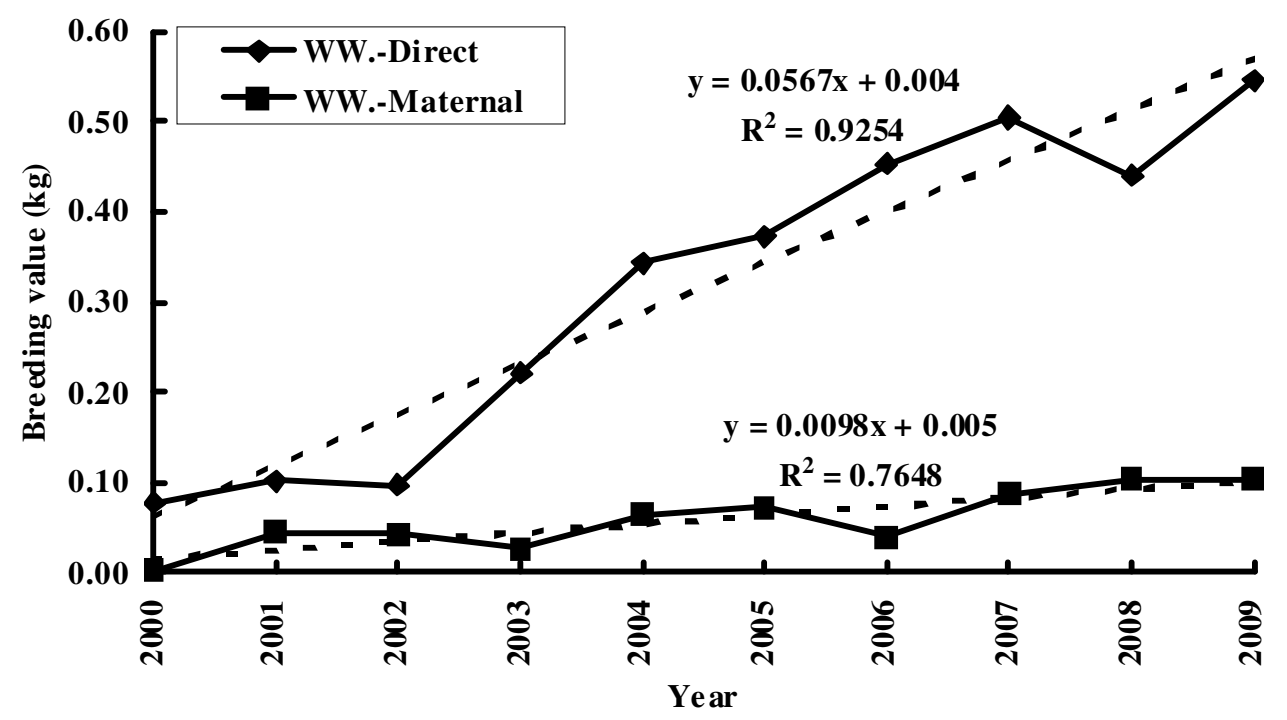

Figure 2 Direct and maternal genetic trends in weaning weight (WW) in various Angora goat studs over a 10-year period. 


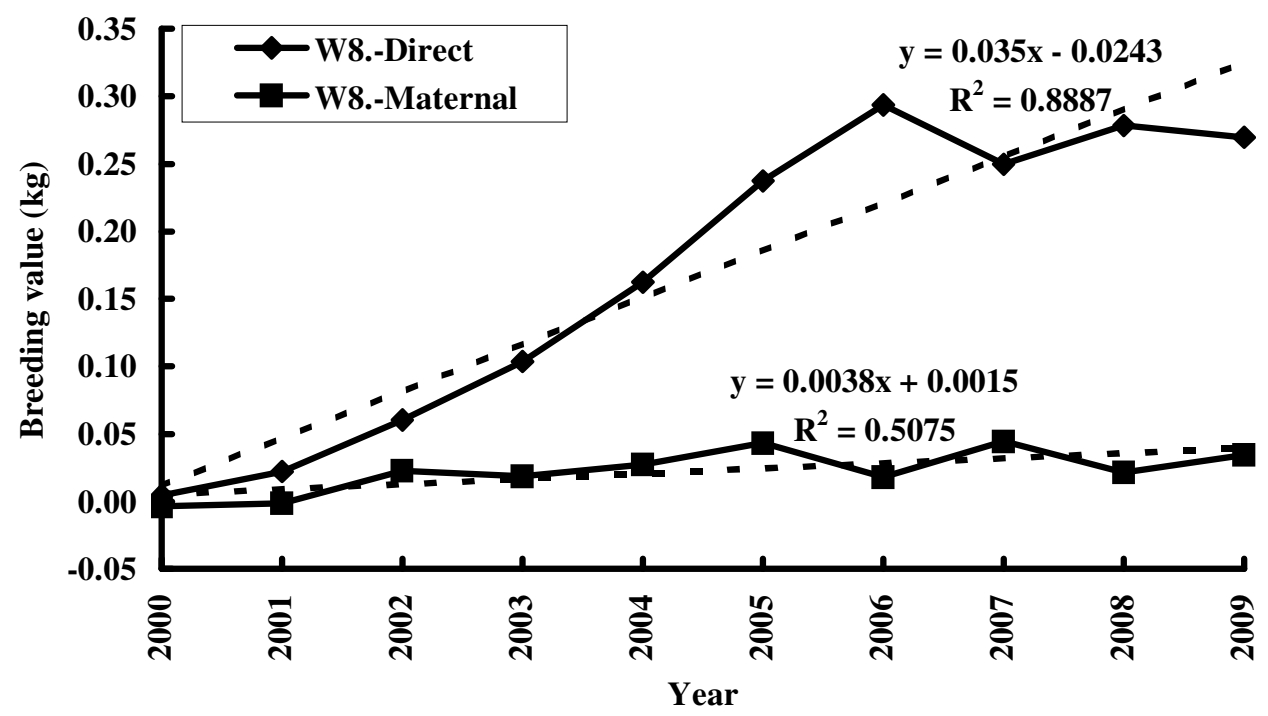

Figure 3 Direct and maternal genetic trends in 8-month body weight (W8) in various Angora goat studs over a 10-year period.

Because young rams are sold at 14 to 16 months while carrying their third fleece, they have to be performance tested at 8 to 9 months at the second shearing. First selection thus took place on 8 -month body weights. At third shearing age, only a fleece sample is taken to determine fibre diameter and body weight is recorded. Selection of sires is then done on a combination of second- and third-shearing performance data. In the case of ewes, selection of young replacement ewes took place at 16 to 18 months on the third shearing data in the South African Angora goat industry.

Thus, the only body weights at which some selection is practised are 8-month and 16-month weights. The lower direct genetic correlations of birth weight with body weight at the older ages resulted in there being very little correlated response in birth weight, compared with the responses in weaning weight and 12-month weight. The latter body weights had much higher direct genetic correlations with the body weights under direct selection.

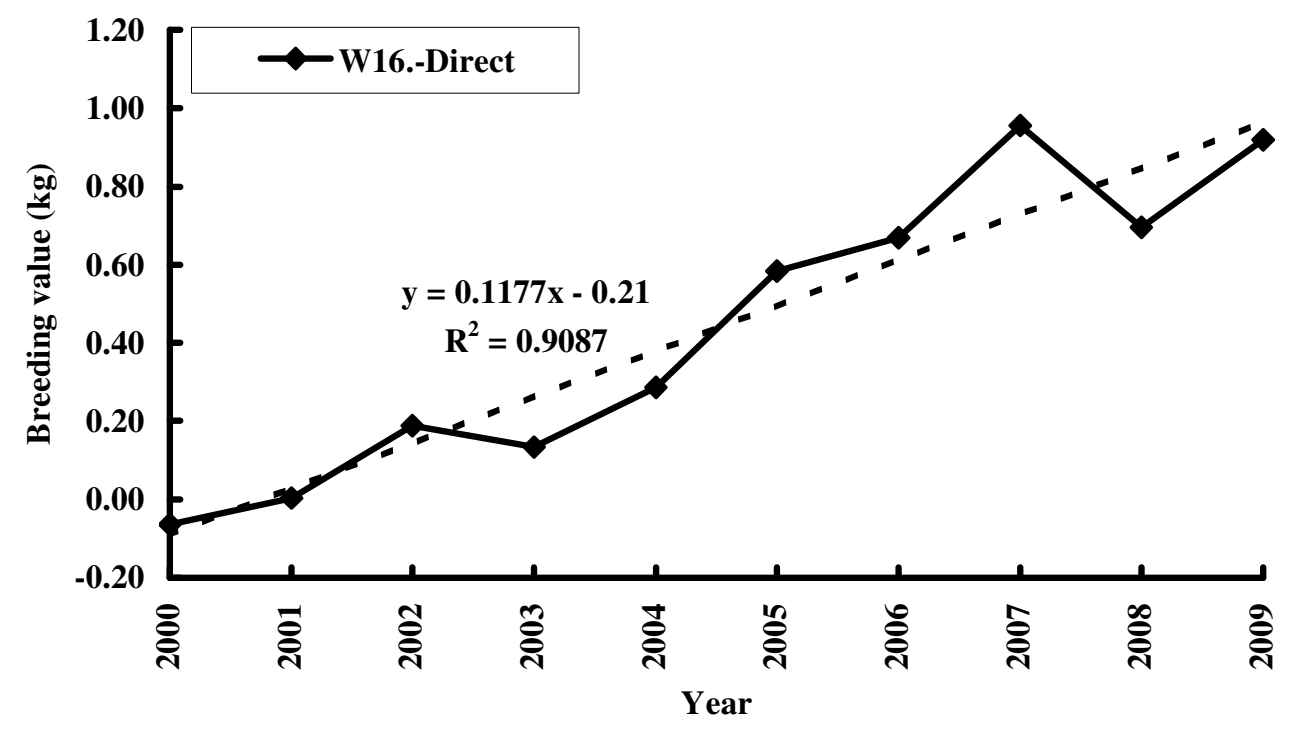

Figure 4 Direct genetic trend in 16-month body weight (W16) in various Angora goat studs over a 10-year period. 


\section{Conclusion}

The genetic analyses of data collected on 11 Angora goat studs indicated that it is possible to increase body weight of Angora kids and young goats through selection. An increase in body weight has occurred in the 11 studs over the 10-year study period, although they did not all use performance testing. This improvement, as well as an improvement in birth weight, linked to kid survival rate, could be enhanced when more breeders use objective selection on body weight. The high heritability estimated for 16-month body weight indicated that selection for increased body weight at this age should be successful. Furthermore, selection for increased 16-month body weight should have a positive effect on body weight earlier in life, and could contribute indirectly to improved kid survivability.

Because reproduction and body weight should be included in a selection programme for Angora goats, the relationship between the direct and maternal additive effects should be clarified. The importance of a sufficiently structured and related pedigree, especially on the part of the dams and maternal grand dams, has again been highlighted in this study. As this is one of the constraints of this data set, data collection in the Angora goat industry should continue until a suitably structured data set has been built up, which could be used to estimate multi-trait breeding values for the industry.

\section{Acknowledgements}

The author wants to convey her sincere appreciation to the participating Angora goat breeders for their collaboration in this project and to Mohair South Africa for funding the project.

\section{References}

Analla, M., Munoz-Serrano, A. \& Serradilla, J.M., 1999. Comparison of the simple breeding value model and the maternal effects model for genetic evaluation of Segurena lambs. Anim. Sci. 68, 427-432.

Bosso, N.A., Cissé, M.F., Van der Waaij, E.H., Fall, A. \& Van Arendonk, J.A.M., 2007. Genetic and phenotypic parameters of body weight in West African Dwarf goat and Djallonké sheep. Small Rumin. Res. 67, 271-278.

Boujenane, I. \& Hazzab, A.E., 2008. Genetic parameters for direct and maternal effects on body weights of Draa goats. Small Rumin. Res. 80, 16-21.

Gerstmayr, S., 1991. Impact of the data structure on the reliability of the estimated genetic parameters in an animal model with maternal effects. J. Anim. Breed. Genet. 109, 321-336.

Gerstmayr, S. \& Horst, P., 1995. Estimates of performance traits in Turkish Angora goats. Small Rumin. Res. 16, 141-157.

Gifford, D.R., Ponzoni, R.W., Lampe, R.J. \& Burr, J., 1991. Phenotypic and genetic parameters of fleece traits and live weight in South Australian Angora goats. Small Rumin. Res. 4, 293-302.

Gilmour, A.R., Gogel, B.J., Cullis, B.R. \& Thompson, R., 2009. ASReml User Guide Release 3.0 VSN International Ltd, Hemel Hempstead, HPI 1ES, UK.

Gowane, G.R., Chopra, A., Prakash, V. \& Arora, A.L., 2011. Estimates of (co)variance components and genetic parameters for growth traits in Sirohi goat. Trop. Anim. Health Prod. 43, 189-198.

Hagger, C. \& Schneeberger, M., 1995. Influences of amount of pedigree information on computing time and of model assumptions on restricted maximum likelihood estimates of population parameters in Swiss BlackBrown Mountain sheep. J. Anim. Sci. 73, 2213-2219.

Iwaisaki, H., Tsuruta, S., Misztal, I. \& Bertrand, J.K., 2005. Estimation of correlation between maternal permanent environmental effects of related dams in beef cattle. J. Anim. Sci. 83, 537-542.

Larsgard, A.G. \& Olesen, I., 1998. Genetic parameters for direct and maternal effects on weights and ultrasonic muscle and fat depth of lambs. Livest. Prod. Sci. 55, 273-278.

Lewis, R.M. \& Beatson, P.R., 1999. Choosing maternal-effect models to estimate (co)variances for live and fleece weight in New Zealand Coopworth sheep. Livest. Prod. Sci. 58, 137-150.

Ligda, Ch., Gabriilidis, G., Papadopoulos, Th. \& Georgoudis, A., 2000. Investigation of direct and maternal genetic effects on birth and weaning weight of Chios lambs. Livest. Prod. Sci. 67, 75-80.

Mandal, A., Neser, F.W.C., Rout, P.K., Roy, R. \& Notter, D.R., 2006. Estimation of direct and maternal (co)variance components for pre-weaning growth traits in Muzaffarnagari sheep. Livest. Prod. Sci. 99, 79-89.

Mandal, A., Roy, R. \& Rout, P.K., 2008. Direct and maternal effects for body measurements at birth and weaning 
in Muzaffarnagari sheep of India. Small Rumin. Res. 75, 123-127.

Maniatis, N. \& Pollott, G.E., 2003. The impact of data structure on genetic (co)variance components of early growth in sheep, estimated using an animal model with maternal effects. J. Anim. Sci. 81, 101-108.

Meyer, K., 1992. Variance components due to direct and maternal effects for growth traits of Australian beef cattle. Livest. Prod. Sci. 31, 179-204.

Miraei-Ashtiani, S.R., Seyedalian, S.A.R. \& Moradi Shahrbabak, M., 2007. Variance components and heritabilities for body weight traits in Sangsari sheep, using univariate and multivariate animal models. Small Rumin. Res. 73, 109-114.

Morrell, C.H., 1998. Likelihood ratio testing of variance components in the linear mixed effects model using restricted maximum likelihood. Biometrics 54, 1560-1568.

Nicoll, G.B., 1985. Estimates of environmental effects and some genetic parameters for weaning weight and fleece weights of young Angora goats. Proc. N. Z. Soc. Anim. Prod. 45, 217-219.

Nicoll, G.B., Bigham, M.L. \& Alderton, M.J., 1989. Estimates of environmental effects and genetic parameters for live weights and fleece traits of Angora goats. Proc. N. Z. Soc. Anim. Prod. 49, 183-189.

Norris, D., Banga, C., Benyi, K. \& Sithole, B.C., 2004. Estimation of genetic parameters and variance components for growth traits of Nguni cattle in Limpopo Province, South Africa. Trop. Amin. Health Prod. 36, 801-806.

Rashidi, A., Bishop, S.C. \& Matika, O., 2011. Genetic parameter estimates for pre-weaning performance and reproduction traits in Markhoz goats. Small Rumin. Res. 100, 100-106.

Robinson, D.L., 1996. Models which might explain negative correlations between direct and maternal genetic effects. Livest. Prod. Sci. 45, 111-122.

Safari, A. \& Fogarty, N.M., 2003. Genetic parameters for sheep production traits. Estimates from the literature. NSW Agriculture, Orange Agricultural Institute, Orange, NSW, 2800, Australia. Australian Sheep Industry Cooperative Research Centre. pp. 13-21.

Safari, E., Fogarty, N.M. \& Gilmour, A.R., 2005. A review of genetic parameter estimates for wool, growth, meat and reproduction traits in sheep. Livest. Prod. Sci. 92, 271-289.

Safari, E., Fogarty, N.M., Gilmour, A.R., Atkins, K.D., Mortimer, S.I., Swan, A.A., Brien, F.D., Greeff, J.C. \& Van der Werf, J.H.J., 2007. Across population genetic parameters for wool, growth, and reproduction traits in Australian Merino sheep. 2. Estimates of heritability and variance components. Aust. J. Agric. Res. 58, 177-184.

SAS, 2009. SAS OnlineDoc® 9.2. SAS Institute Inc., Cary, N.C., USA.

Snyman, M.A., 2007. Body weight and growth rate of South African Angora goat kids under different pre- and post weaning management systems. S. Afr. J. Anim. Sci. 37, 132-141.

Snyman, M.A., 2010a. Influence of body weight, age and management system on reproduction of South African Angora goat does. S. Afr. J. Anim. Sci. 40, 41-53.

Snyman, M.A., 2010b. Factors affecting pre-weaning kid mortality in South African Angora goats. S. Afr. J. Anim. Sci. 40, 54-64.

Snyman, M.A. \& Olivier, J.J., 1996. Genetic parameters for body weight, fleece weight and fibre diameter in South African Angora goats. Livest. Prod. Sci. 47, 1-6.

Snyman, M.A. \& Olivier, J.J., 1999. Repeatability and heritability of objective and subjective fleece traits and body weight in South African Angora goats. Small Rumin. Res. 34, 103-109.

Snyman, M.A., Erasmus, G.J., Van Wyk, J.B. \& Olivier, J.J., 1995. Direct and maternal (co)variance components and heritability estimates for body weight at different ages and fleece traits in Afrino sheep. Livest. Prod. Sci. 44, 229-235.

Snyman, M.A., Olivier, J.J. \& Wentzel, D., 1996. Breeding plans for South African Angora goats. Angora Goat and Mohair Journal 38 (1), 23-31.

Vaez Torshizi, R., Nicholas, F.W. \& Raadsma, H.W., 1996. REML estimates of variance and covariance components for production traits in Australian Merino sheep, using an animal model. 1. Body weight from birth to 22 months. Aust. J. Agric. Res. 47, 1235-1249.

Van Wyk, J.B., Swanepoel, J.W., Cloete, S.W.P., Olivier, J.J. \& Delport, G.J., 2008. Across flock genetic parameters for yearling body weight and fleece traits in the South African Dohne Merino population. S. Afr. J. Anim. Sci. 38, 31-37.

Yalçin, B.C., 1982. Angora goat breeding. Proc. 3rd Int. Conf. Goat Prod. Disease, Tucson, Arizona. 
Yazdi, M.H., Engström, G., Näsholm, A., Johansson, K., Jorjani, H. \& Liljedahl, L.E., 1997. Genetic parameters for lamb weight at different ages and wool production in Baluchi sheep. Anim. Prod. 65, 247-255.

Zhang, C., Yang, L. \& Shen, Z., 2008. Variance components and genetic parameters for weight and size at birth in the Boer goat. Livest. Sci. 115, 73-79. 